\title{
Saco hermético e filme plástico na conservação de pimentão verde, sob condições de armazenamento ambiente
}

O pimentão (Capsicum annum L.) é uma hortaliça altamente perecível, o que reduz a sua vida pós-colheita, caso não seja conservada adequadamente. Objetivou analisar a eficiência de diferentes revestimentos plásticos sobre a conservação pós-colheita do pimentão verde. Os pimentões foram adquiridos na CEASA de São Luís (MA) e encaminhados ao laboratório. O delineamento utilizado foi o inteiramente casualizado, em parcela subdividida no tempo (3, 6, 9 e 12 dias de armazenamento), com três tratamentos (sem embalagem, filme plástico e saco hermético), quatro repetições e dois frutos por parcela (bandeja). Os pimentões foram armazenados sobre bancada, em condição ambiente $\left(T= \pm 25^{\circ} \mathrm{C} \cdot \mathrm{UR}=48 \%\right)$, durante 12 dias. Avaliaram-se a perda de massa fresca, acidez total titulável (ATT), pH e sólidos solúveis totais, bem como suas correlações no amadurecimento do pimentão. Ao término do estudo, recomenda-se o uso de saco hermético na conservação pós-colheita de pimentão verde, pois esta tecnologia propicia conservação de importantes atributos de qualidade, como a massa fresca, acidez pH e sólidos solúveis, durante 12 dias de armazenamento ambiente. Isso pode reduzir perdas quantitativas e/ou qualitativas, com reflexos positivos nos indicadores socioeconômicos e ambientais da comercialização de pimentão verde.

\section{Hermetic bag and plastic film in the conservation of green peppers, under environmental storage conditions}

\begin{abstract}
Pepper (Capsicum annum L.) is a highly perishable vegetable, which reduces its post-harvest life if not properly preserved. The objective was to analyze the efficiency of different plastic coatings on postharvest conservation of green peppers. The peppers were purchased at CEASA in São Luís (MA) and sent to the laboratory. The design used was completely randomized, in a split subdivided over time (3, 6, 9 and 12 days of storage), with three treatments (without packaging, plastic film and airtight bag), four replicates and two fruits per portion (tray). The peppers were stored on a bench, in ambient condition ( $\mathrm{T}= \pm 25^{\circ} \mathrm{C} ; \mathrm{RH}=48 \%$ ), for 12 days. Fresh weight loss, total titratable acidity (TTA), $\mathrm{pH}$ and total soluble solids were evaluated, as well as their correlations in the ripening of peppers. At the end of the study, the use of an airtight bag is recommended for postharvest conservation of green peppers, as this technology provides conservation of important quality attributes, such as fresh mass, acidity, $\mathrm{pH}$ and soluble solids, during 12 days of storage environment. This can reduce quantitative and/or qualitative losses, with positive effects on the socioeconomic and environmental indicators of the marketing of green peppers.
\end{abstract}

Keywords: Capsicum annum L.; Post-harvest; Quality; Plastic coating.

Francisco Ivo dos Santos Aguiar (iD)

Universidade Federal Rural do Rio de Janeiro, Brasil http://lattes.cnpq.br/8032950952713754 http://orcid.org/0000-0001-9449-7174 ivoaguiar222@hotmail.com

Marcelo de Sousa da Silva (iD)

Universidade Federal do Maranhão, Brasil http://lattes.cnpq.br/5929903987543113 http://orcid.org/0000-0002-6074-8761 marcelosousamj@hotmail.com

Francisco Gilvan Borges Ferreira Freitas Júnior (iD) Universidade Federal do Maranhão, Brasil http://lattes.cnpq.br/5174137410180479 http://orcid.org/0000-0002-8306-0310 gilvanjr582@gmail.com

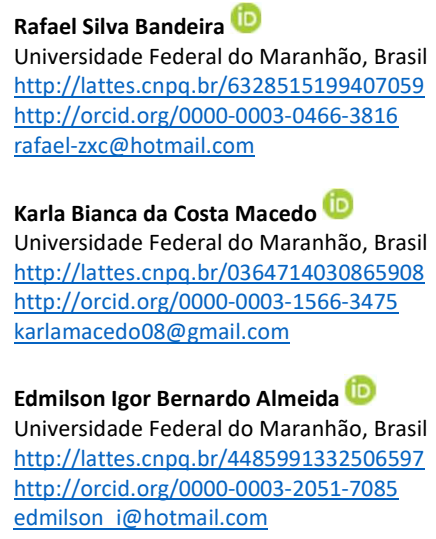
http://lattes.cnpq.br/6328515199407059 http://orcid.org/0000-0003-0466-3816 rafael-zxc@hotmail.com

Karla Bianca da Costa Macedo (iD

Universidade Federal do Maranhão, Brasil http://lattes.cnpq.br/0364714030865908 http://orcid.org/0000-0003-1566-3475 karlamacedo08@gmail.com

Edmilson Igor Bernardo Almeida (ic) Universidade Federal do Maranhão, Brasil http://lattes.cnpq.br/4485991332506597 http://orcid.org/0000-0003-2051-7085 edmilson_i@hotmail.com

\section{Augusto Cézar Vieira Neves Júnior (iD) Universidade Estadual do Maranhão, Brasil http://lattes.cnpq.br/8398353131314491 http://orcid.org/0000-0002-1438-5859 gutocesar@hotmail.com \\ Leonardo Bernardes Taverny de Oliveira Universidade Federal do Maranhão, Brasil http://lattes.cnpq.br/5822293050229432 http://orcid.org/0000-0002-2971-2066 tavernyzoot@yahoo.com.br \\ Moisés Rodrigues Martins (iD \\ Universidade Estadual do Maranhão, Brasil http://lattes.cnpq.br/4535860291126884 http://orcid.org/0000-0002-7567-7505 \\ moisesmartins@professor.uema.br}

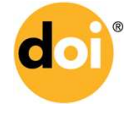

DOI: 10.6008/CBPC2179-6858.2021.002.0052
Referencing this:

AGUIAR, F. I. S.; SILVA, M. S.; FREITAS JÚNIOR, F. G. B. F.; BANDEIRA, R. S.; ALMEIDA, E. I. B.; NEVES JÚNIOR, A. C. V.; OLIVEIRA, L. B. T.; MARTINS, M. R.. Saco hermético e filme plástico na conservação de pimentão verde, sob condições de armazenamento ambiente. Revista Ibero Americana de Ciências Ambientais, v.12, n.2, p.603-610, 2021. DOI: http://doi.org/10.6008/CBPC2179-6858.2021.002.0052 


\section{INTRODUÇÃO}

O pimentão (Capsicum annum L.) é uma hortaliça-fruto pertencente à família Solanaceae e consiste numa das hortaliças mais consumidas no Brasil (MONTEIRO NETO et al., 2016). O Brasil possui produtividade média de $22 \mathrm{t} \mathrm{ha}^{-1}$, com área de cultivo de 15.000 ha e produção anual de 334.615 toneladas, alcançando a posição de 15 em área plantada e 2 o lugar em produtividade de pimentão no mundo (ROCHA, 2017).

O pimentão é um fruto climatérico, com pico de etileno e respiração mesmo após o desligamento da planta-mãe (CHAGAS et al., 2018). Trata-se de uma hortaliça altamente perecível, pois apresenta propensão a deteriorar-se rapidamente, em virtude de distúrbios fisiológicos e/ou microbiológicos, que diminuem a sua vida pós-colheita e aumenta as perdas na comercialização (MOREIRA et al., 2017).

Como forma de reduzir perdas pós-colheita oriundas de diferentes causas primárias, especialmente as desordens fisiológicas e contaminações microbiológicas, é importante a adoção de técnicas de armazenamento, como a atmosfera modificada. A qual consiste na utilização de embalagens plásticas ou comestíveis que originam uma barreira artificial sobre o fruto, reduzindo seu metabolismo pós-colheita (OSHIRO et al., 2012; VESPUCCl et al., 2018).

A seleção da embalagem ideal varia conforme a sua capacidade em reduzir as trocas gasosas entre o fruto e o ambiente, durante o maior período de tempo possível. A permeabilidade do filme aos gases e vapor de água, e o poder de manter a integridade da selagem são essenciais para prolongar a vida útil do produto (SANCHES et al., 2015). Segundo Freitas Júnior et al. (2020), a utilização de embalagens plásticas, destacadamente o filme plástico e sacos hermético permite ótima conservação de frutas e hortaliças, cujos resultados ainda são incipientes para o pimentão.

Aguiar et al. (2020a) enfatizaram que o uso destas tecnologias pode ser bastante viável para pequenos comerciantes, principalmente em que a renda mensal não supera dois salários mínimos e se enquadra com o perfil socioeconômico estimado por Almeida et al. (2020) para 27 cidades maranhenses em que o pimentão se apresentou como uma das hortaliças mais ofertadas e perdidas. Diante do exposto, objetivou-se analisar a eficiência de diferentes revestimentos plásticos sobre a conservação pós-colheita do pimentão verde.

\section{MATERIAIS E MÉTODOS}

O experimento foi conduzido no Laboratório de Fitotecnia e Pós-Colheita, Universidade Estadual do Maranhão (UEMA), Campus de São Luís (MA), no período janeiro a fevereiro de 2019. Os pimentões foram adquiridos na CEASA de São Luís (MA) e encaminhados ao laboratório, onde foram selecionados em função do tamanho, cor e ausência de danos; lavados e sanificados com hipoclorito de sódio a 200 ppm, por 15 minutos, em água potável a $12^{\circ} \mathrm{C}$. Após secagem à temperatura ambiente, os frutos foram separados aleatoriamente em 65 grupos de 2 unidades, e acondicionados em bandejas de isopor, conforme disposição dos tratamentos.

O delineamento experimental foi o inteiramente casualizado, em parcela subdividida no tempo (3, 
6, 9 e 12 dias de armazenamento), com três tratamentos (sem embalagem, filme plástico e saco hermético), quatro repetições e dois frutos por parcela (bandeja). Os pimentões foram armazenados sobre bancada, em condição ambiente $\left(T= \pm 25^{\circ} \mathrm{C} ; U R=48 \%\right)$, durante 12 dias.

Para a caracterização física, aferiu-se o diâmetro longitudinal $(\mathrm{mm})$, diâmetro transversal $(\mathrm{mm})$, massa fresca (g) e perda de massa fresca (\%). Os diâmetros longitudinal e transversal foram aferidos através de paquímetro digital, ao passo que a massa fresca, em balança semi-analítica. A perda de massa fresca foi estimada pela seguinte fórmula:

$$
\operatorname{PMF}(\%)=\frac{(\text { Massa Inicial }- \text { Massa a cada intervalo de tempo) }}{\text { Massa inicial }} \times 100
$$

*fórmula de determinação de perda de massa a cada intervalo de análise. Em que, PMF $\rightarrow$ Perda de massa fresca (\%).

A análise química foi realizada através de maceração de cada tratamento, a cada três dias. $O$ teor de sólidos solúveis totais (SST) ('Brix) foi determinado pela leitura do suco homogeneizado em refratômetro digital. O potencial hidrogeniônico $(\mathrm{pH})$, pelo método potenciômetro em dispositivo de $\mathrm{pH}$ digital, através de calibrações em soluções tampão, a pH 4,0 e 7,0, conforme ISO (2003). A acidez total titulável (ATT) (\% ácido cítrico), através da titulação em solução padrão de hidróxido de sódio $(0,1 \mathrm{~N})$.

Os dados foram submetidos à análise de variância pelo teste $F(p<0,05)$ e para os casos em que a hipótese de nulidade foi rejeitada procedeu-se com a comparação de médias pelo teste Duncan. Adicionalmente foi aplicado teste multidimensional de componentes principais para avaliar os níveis de correlação entre as variáveis perda de massa fresca, acidez total titulável, sólidos solúveis totais e pH, sobre o amadurecimento do pimentão verde.

\section{RESULTADOS E DISCUSSÃO}

Os pimentões apresentaram diâmetro longitudinal com amplitude de 86 a $148 \mathrm{~mm}$, cujas maiores frequências absoluta (39 amostras) e relativa (81,00\%) foram observadas na classe 2 (107 a 127 mm). Apenas, 6,12 e 13,00\% das amostras foram ordenadas nas classes 1 e 3, respectivamente (Tabela1).

Tabela 1: Caracterização do diâmetro longitudinal de pimentão verde submetido a armazenamento com diferentes revestimentos plásticos.

\begin{tabular}{llllll}
\hline Classe & Intervalo $(\mathrm{mm})$ & FA & FAA & FR & FRA \\
\hline 1 & $86-106$ & 3 & 3 & 6,12 & 6,12 \\
2 & $107-127$ & 39 & 42 & 81,00 & 87,71 \\
3 & $128-148$ & 6 & 48 & 13,00 & 100,00 \\
\hline
\end{tabular}

FA - Frequência Absoluta (amostras); FAA - Frequência Absoluta Acumulada (amostras); FR - Frequência Relativa (\%); FRA - Frequência Relativa Acumulada (\%).

Os valores estão dentro do padrão comercial brasileiro para diâmetro longitudinal, estimado em 80 a $130 \mathrm{~mm}$ e reportado por Aguiar et al. (2020b). As amostras de maior frequência absoluta e relativa pertencem, segundo a classificação da HORTBRASIL, à Classe 10, que é caracterizada por diâmetro longitudinal de 101 a 120 mm. Em relação ao diâmetro transversal, constatou-se amplitude de 40 a $57 \mathrm{~mm}$. As maiores frequências absoluta (24 amostras) e relativa (48,98\%) foram estimadas para classe 2 (46 a 51 $\mathrm{mm}$ ). Diferentemente dos dados de diâmetro longitudinal que se distribuíram predominantemente na classe 
2, a classificação foi mais segmentada para o diâmetro transversal. Com participação relevante da classe 3, cuja frequência relativa foi estimada em 38,78\%, equivalente a 18 amostras (Tabela 2 ).

Tabela 2: Caracterização do diâmetro transversal de pimentão verde submetido a armazenamento com diferentes revestimentos plásticos.

\begin{tabular}{llllll}
\hline Classe & Intervalo $(\mathrm{mm})$ & FA & FAA & FR & FRA \\
\hline 1 & $40-45$ & 6 & 6 & 12,24 & 12,44 \\
2 & $46-51$ & 24 & 30 & 48,98 & 61,22 \\
3 & $52-57$ & 18 & 48 & 38,78 & 100,00 \\
\hline
\end{tabular}

FA - Frequência Absoluta (amostras); FAA - Frequência Absoluta Acumulada (amostras); FR - Frequência Relativa (\%); FRA - Frequência Relativa Acumulada (\%).

De acordo com a classificação da HORTBRASIL, os pimentões analisados estão em conformidade com o grupo cônico, pois tem diâmetro longitudinal superior ao transversal. Bem como, podem ser enquadradas na subclasse 4, cujos diâmetros transversais variam de 40 a $60 \mathrm{~mm}$. Nesse aspecto, os frutos comercializados na CEASA de São Luís (MA) são do grupo cônico, classe 10 e subclasse 4, conforme a HORTBRASIL.

Estes resultados corroboram com Aguiar et al. (2020b) que ao avaliar a qualidade de pimentões comercializados em feiras livres, supermercados e sacolões de Chapadinha (MA) evidenciaram a mesma classificação. O que pode ter relação com a procedência dos hortifrútis comercializados no Maranhão, que segundo Almeida et al. (2020) é predominantemente de outros estados, como o Ceará, Bahia e Pernambuco.

No que diz respeito ao armazenamento, observou-se efeito significativo $(p<0,05)$ da interação tratamento-tempo para o pH e teor de sólidos solúveis totais, ao passo que a perda de massa sofreu efeitos individuais do tratamento e tempo, e a acidez titulável total, apenas do tempo. Aos 12 dias de armazenamento, a perda de massa fresca variou de 4,07 a 15,93\% (Tabela 3).

Tabela 3: Comparação de médias e resumo da ANOVA para perda de massa fresca (\%) em pimentão verde armazenado sob diferentes tratamentos e tempo de prateleira.

\begin{tabular}{|c|c|c|c|c|c|c|c|c|}
\hline Tratamento & Tempo & & & & & Trat. & Tempo & Trat.*Tempo \\
\hline & 3 & 6 & 9 & 12 & Média & & $p$ & \\
\hline Controle & $8,90 \mathrm{Ab}$ & $11,05 \mathrm{Ab}$ & $11,88 \mathrm{Ab}$ & $15,93 \mathrm{Aa}$ & $11,94^{a}$ & $0,001^{* *}$ & $0,001 * *$ & $0,16^{\mathrm{NS}}$ \\
\hline $\mathrm{FP}$ & $7,22 A C$ & $8,89 \mathrm{Abc}$ & 11,98Aab & $14,48 \mathrm{Aa}$ & $10,64^{a}$ & & & \\
\hline SH & 1,39Ba & $3,42 \mathrm{Ba}$ & $4,07 \mathrm{Ba}$ & 4,07Ba & $3,24 \mathrm{~B}$ & & & \\
\hline Média & $5,84 c$ & $7,78 b$ & $9,31 b$ & $11,49 a$ & & CV(\%): & 2,19 & \\
\hline
\end{tabular}

Trat. = Tratamento; FP = Filme Plástico; $\mathrm{SH}$ = Saco Hermético; ${ }^{\text {NS }}$ = Não significativo; * = Significativo a 5\% de significância; ** = Significativo a $1 \%$ de significância; $\mathrm{CV}=$ Coeficiente de Variação; Médias seguidas de letras maiúsculas iguais na coluna e letras minúsculas iguais na linha, não diferiram estatisticamente entre si.

A perda de massa estimada com o uso de saco hermético em todos os dias, especialmente aos 12 dias de armazenamento (4,07\%), corroborou com o limite aceitável de 5 a 10\% recomendado por Silva et al. (2011) para produtos hortícolas (Tabela 3). Enquanto para o filme plástico $(14,48 \%)$ e controle $(15,93 \%)$, os valores foram superiores a esta faixa, o que segundo alguns autores, pode aumentar o enrugamento na epiderme do pimentão e torná-lo indesejável para compra/consumo, dependendo do nível de exigência dos consumidores. Em face disso, Guerra et al. (2014), Almeida et al. (2012) e Ribeiro et al. (2011) reportaram que a perda de massa e enrugamento consistiram nas principais desordens fisiológicas que acarretaram perdas pós-colheita no pimentão comercializado na rede varejista de Santarém (PA), Areia (PB) e na Central de Abastecimento de Campina Grande (EMPASA - PB). 
O saco hermético se comportou com uma tecnologia eficaz e apresentou $390 \%$ menos, perda de massa fresca que os demais tratamentos, aos 12 dias de armazenamento (Tabela 3). De acordo com Sanches et al. (2015), o efeito positivo do saco hermético deve-se à manutenção da umidade relativa no interior da embalagem, o que impede um aumento no déficit de pressão de vapor e, consequentemente, diminuiu a perda de água por transpiração. Em consonância, Damatto Júnior et al. (2010) relataram que o uso de embalagens protetoras também pode reduzir a taxa de respiração e quando esses dois fatores são controlados adequadamente, há retardamento da senescência. A acidez total titulável variou apenas em função do tempo, não sendo detectados efeitos significativos dos tratamentos sobre esta variável (Tabela 4).

Tabela 4: Comparação de médias e resumo da ANOVA para acidez titulável total (\% de ácido cítrico) em pimentão verde armazenado sob diferentes tratamentos e tempo de prateleira.

\begin{tabular}{|c|c|c|c|c|c|c|c|c|}
\hline Trat. & Tempo & & & & & Trat. & Temp. & Trat.*temp. \\
\hline & 3 & 6 & 9 & 12 & Média & & $p$ & \\
\hline Controle & $0,08 \mathrm{Ab}$ & $0,08 \mathrm{Ab}$ & $0,07 A b$ & $0,12 \mathrm{Aa}$ & 0,09 & $0,27^{\mathrm{NS}}$ & $0,0001^{*}$ & $0,10^{\mathrm{NS}}$ \\
\hline $\mathrm{FP}$ & $0,07 A c$ & $0,10 A b$ & $0,08 \mathrm{Abc}$ & $0,12 A a$ & 0,09 & & & \\
\hline $\mathrm{SH}$ & $0,08 \mathrm{Ab}$ & $0,10 A a b$ & 0,09Aab & $0,11 \mathrm{Aa}$ & 0,09 & & & \\
\hline Média & $0,08 c$ & $0,09 b$ & $0,08 b c$ & $0,12 \underline{a}$ & & $\mathrm{CV}(\%):$ & 14,46 & \\
\hline
\end{tabular}

Trat. = Tratamento; FP = Filme Plástico; $\mathrm{SH}=$ Saco Hermético; ${ }^{\text {NS }}=$ Não significativo; * = Significativo a $5 \%$ de significância; ** = Significativo a 1\% de significância; CV = Coeficiente de Variação; Médias seguidas de letras maiúsculas iguais na coluna e letras minúsculas iguais na linha, não diferiram estatisticamente entre si.

Em todos os tratamentos e aos 12 dias de armazenamento, evidenciou-se leve aumento na concentração de ácidos orgânicos, similarmente observado por Moreira et al. (2017) em estudo com filmes comestíveis na conservação pós-colheita do pimentão 'Magali'. Conforme reportado por Vilas-Boas et al. (2012), a pequena variação e/ou ausentes efeitos dos tratamentos sobre a acidez titulável podem estar relacionados ao baixo metabolismo respiratório pós-colheita do pimentão, que consiste num fruto com pouco acúmulo de reservas energéticas, como o amido. Por consequência não há efeito expressivo sobre o acúmulo de ácidos orgânicos, diferentemente do que ocorre com o tomate, no qual Ferreira et al. (2010) observaram aumento gradativo de ATT ao longo de 15 dias de armazenamento. De forma antagônica à ATT, o pH apresentou decréscimo ao longo do tempo de armazenamento, especialmente aos 12 dias (Tabela 5).

Tabela 5: Comparação de médias e resumo da ANOVA para o pH da polpa de pimentão verde armazenado sob diferentes tratamentos e tempo de prateleira.

\begin{tabular}{|c|c|c|c|c|c|c|c|c|}
\hline Tratamento & Tempo & & & & & Trat. & Tempo & Trat. ${ }^{*}$ Tempo \\
\hline & 3 & 6 & 9 & 12 & Média & & $p$ & \\
\hline Controle & $6,16 \mathrm{Ab}$ & $6,26 \mathrm{Aab}$ & $6,49 \mathrm{Aa}$ & $5,69 A C$ & 6,15 & $0,33^{\mathrm{NS}}$ & $0,0001 * *$ & $0,039 *$ \\
\hline $\mathrm{PF}$ & $6,28 \mathrm{Aa}$ & 6,10Aab & 6,04Bab & $5,89 A b$ & 6,08 & & & \\
\hline $\mathrm{SH}$ & $6,08 \mathrm{Aa}$ & $6,06 \mathrm{Aa}$ & $6,10 \mathrm{Ba}$ & $5,83 \mathrm{Aa}$ & 6,02 & & & \\
\hline Média & $6,18 a$ & $6,14 a$ & $6,21 a$ & $5,80 \mathrm{~b}$ & & CV (\%): & 3,17 & \\
\hline
\end{tabular}

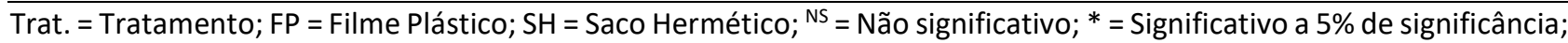
** = Significativo a $1 \%$ de significância; CV = Coeficiente de Variação; Médias seguidas de letras maiúsculas iguais na coluna e letras minúsculas iguais na linha, não diferiram estatisticamente entre si.

Esses resultados corroboraram com Almeida (2010), que observaram relação inversa entre o acúmulo de ácido cítrico e o pH de pimentões revestidos com fécula de batata durante 15 dias de armazenamento. $\mathrm{O}$ pH estimado para todos os tratamentos foi inferior a 6,16 e enquadrou-se com a faixa de frutos não ácidos, citada na classificação estabelecida por Gould (1974). O autor explicou que o pH do 
pimentão atinge 6,52 no fruto verde imaturo e depois tende a diminuir até 5,02, quando o fruto amadurece.

Isso pode explicar a redução do pH em cada tempo de avaliação, principalmente aos 12 dias, quando provavelmente os frutos estariam amadurecidos ou próximos deste estádio de maturação. $\mathrm{O}$ pH de referência para frutos maduros $(5,02)$ pode não ter sido alcançado em decorrência do tempo de armazenamento e/ou pelo efeito tamponante do fluído celular (MOREIRA et al., 2017), os quais possivelmente não permitiram reduções mais drásticas no pH. Todavia, é importante ressaltar que em valores absolutos, as médias para saco hermético e filme plástico foram superiores ao controle e podem designar efeito positivo destas embalagens sobre o retardamento do amadurecimento do pimentão.

O teor de sólidos solúveis oscilou em função dos tratamentos e tempo de armazenamento. Aos 12 dias, obteve-se variação de 2,92 a $3,35^{\circ} \mathrm{Brix}$, representados pelo uso de saco hermético e o controle (sem embalagem) (Tabela 6).

Tabela 6: Comparação de médias e resumo da ANOVA para o teor de sólidos solúveis totais ( ${ }^{\circ}$ Brix) de pimentão verde, analisado em diferentes tratamentos e tempos de armazenamento.

\begin{tabular}{|c|c|c|c|c|c|c|c|c|}
\hline Trat. & Tempo & & & & & Trat. & Tempo & Trat.*Tempo \\
\hline & 3 & 6 & 9 & 12 & Média & & $p$ & \\
\hline Controle & $3,01 \mathrm{Ab}$ & $3,29 \mathrm{Ab}$ & $3,03 \mathrm{Ab}$ & $4,08 \mathrm{Aa}$ & 3,35 a & $0,005 * *$ & $0,01^{*}$ & $0,0001 * *$ \\
\hline FP & $2,96 \mathrm{Aa}$ & $3,08 \mathrm{Aa}$ & $3,18 \mathrm{Aa}$ & $2,94 \mathrm{Ba}$ & $3,04 \mathrm{~B}$ & & & \\
\hline SH & $2,96 \mathrm{Aa}$ & $2,98 \mathrm{Aa}$ & 2,91Aa & $2,82 \mathrm{Ba}$ & $2,92 B$ & & & \\
\hline Média & $2,98 \mathrm{~b}$ & $3,12 \mathrm{ab}$ & $3,04 b$ & $3,28 a$ & & CV (\%) & 6,84 & \\
\hline
\end{tabular}

Trat. = Tratamento; FP = Filme Plástico; $\mathrm{SH}=$ Saco Hermético; ${ }^{\text {NS }}=$ Não significativo; ${ }^{*}=$ Significativo a $5 \%$ de significância; ** = Significativo a 1\% de significância; CV = Coeficiente de Variação; Médias seguidas de letras maiúsculas iguais na coluna e letras minúsculas iguais na linha, não diferiram estatisticamente entre si.

Esses resultados são similares aos de Chagas et al. (2018), que encontraram variação de 1,34 e 3,80 `Brix em pimentões verdes armazenados em câmara fria. Todavia foram inferiores aos obtidos por Sanches et al. (2015), cuja variação foi de 3,9 a 5,4 ${ }^{\circ}$ Brix. O que pode estar relacionado às tecnologias de armazenamento utilizadas, tempo de armazenamento, cultivar, qualidade inicial, dentre outros aspectos do fruto. $\mathrm{O}$ saco hermético e filme plástico não diferiram estatisticamente aos 12 dias de armazenamento e, portanto, mostraram-se eficazes na estabilização dos sólidos solúveis totais do pimentão. Isso pode estar associado ao retardamento do amadurecimento do fruto, através da redução do metabolismo respiratório. Nesse sentido, Sanches et al. (2015) explicaram que durante o amadurecimento ocorrem reações bioquímicas que aumentam o teor de SST no pimentão, principalmente quando não é conservado adequadamente.

Portanto, com o uso dos revestimentos plásticos houve estabilização dos SST dentro de uma faixa recomendada para consumo, demonstrando a eficiência dos tratamentos estudados. Também por ter havido mitigação dos efeitos de diluição dos açúcares, associados à menor perda de massa fresca (DAMATTO JÚNIOR et al., 2010). Ou seja, aumento da concentração de SST, relacionada à maior perda de água, que de acordo com os resultados obtidos neste estudo, foi $390 \%$ maior em frutos não embalados.

A análise dos componentes principais da correlação entre as variáveis, perda de massa fresca, sólidos solúveis totais (STT), acidez titulável total (ATT) e pH está apresentada na Figura 1. O primeiro componente explica em $54,80 \%$ a variabilidade dos dados, ao passo que o segundo, $20,82 \%$. Pode-se considerar que o 
mapa perceptual bidimensional confeccionado está adequado para analisar as relações existentes entre as variáveis, tendo em vista que explica a maior parte da variabilidade existente e está dentro do limite (F>50\%) recomendado por Sneath et al. (1973).

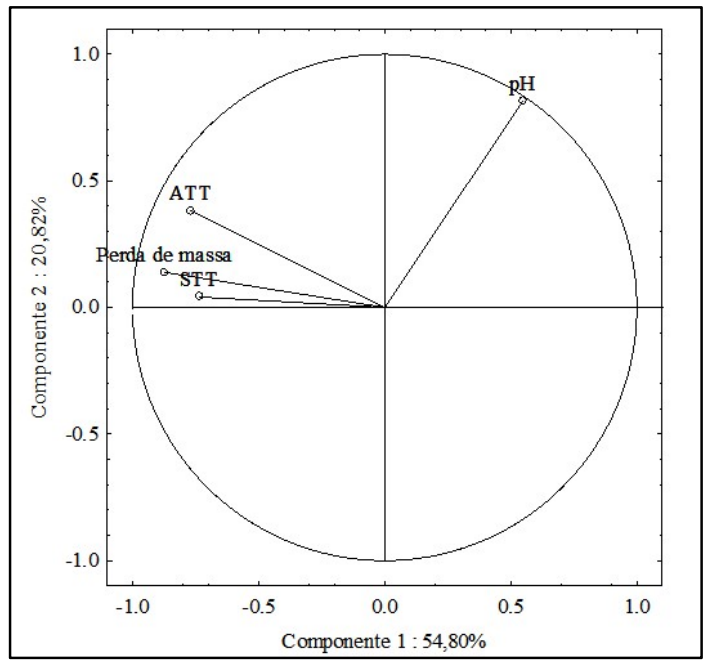

Figura 1: A análise dos componentes.

A perda de massa, ATT e SST comportaram-se de forma similar e em direção oposta ao pH, corroborando com as hipóteses apresentadas anteriormente. Ambas as variáveis apresentaram correlação forte e negativa com a conservação do fruto, especialmente a perda de massa, no primeiro componente. Portanto, quanto maior a perda de massa, menor é o tempo de vida útil do pimentão. Em consonância com Freitas Júnior et al. (2020) e Grigio et al. (2011), os quais explicaram que as pectinas estão relacionadas a resistência dos tecidos que compõe o fruto e, dessa forma, com o aumento do amadurecimento, estas são solubilizadas, induzindo a perda de massa fresca, potencializada pelo incremento das trocas gasosas.

\section{CONCLUSÕES}

Recomenda-se o uso de saco hermético na conservação pós-colheita de pimentão verde, pois esta tecnologia propicia conservação de importantes atributos de qualidade, como a massa fresca, acidez, pH e sólidos solúveis, durante 12 dias de armazenamento em condições ambiente $\left(T= \pm 25^{\circ} \mathrm{C} ; U R=48 \%\right)$. Isso pode reduzir perdas quantitativas e/ou qualitativas, com reflexos positivos nos indicadores socioeconômicos e ambientais da comercialização de pimentão.

AGRADECIMENTOS: À Fundação de Amparo à Pesquisa e ao Desenvolvimento Científico e Tecnológico no Estado do Maranhão pelo auxílio financeiro concedido no Edital Universal 31/2016, processo 960/17.

\section{REFERÊNCIAS}

AGUIAR, F. I. S.; FREITAS JUNIOR, F. G. B. F.; COSTA NETA, C. M.; MACEDO, K. B. C.; ALMEIDA, E. I. B.; NEVES JUNIOR, A. C. V.; ARAUJO, J. R. G.; SILVA, L. R.; OLIVEIRA, L. B. T.; SHIGAKI, F.. Use of Packaging for 'Hawaii' Papaya Conservation, Sold at CEASA of São Luís, Maranhão, Brazil. Journal of

Agricultural Studies, v.8, n.3, p.384-396, 2020a.
DOI: https://doi.org/10.5296/jas.v8i3.16452

AGUIAR, F. I. S.; SILVA, M. S.; MACEDO, K. B. C.; SILVA, M. D. C.; COSTA NETA, C. M.; ALMEIDA, E. I. B.; DOIHARA, I. P.; PIRES, I. C. G.. Pós-colheita, patogenias e destinação final de perdas na comercialização de pimentão verde. Research 
Society and Development, v.9, n.9, p.e50996678, 2020b. DOI: https://doi.org/10.33448/rsd-v9i9.6678

ALMEIDA, D. M.. Biofilme de blenda de fécula de batata e celulose bacteriana na conservação de fruta minimamente processada. Tese (Doutorado em Processos Biotecnológicos Agroindustriais) - Universidade Federal do Paraná, Curitiba, 2010.

ALMEIDA, E. I. B.; FERRÃO, G. E.; MARQUES, J. I.; SOUSA, W. S.. Perdas pós-colheita de frutas e hortaliças no Maranhão: estimativas, causas, impactos e soluções. São Luís: EDUFMA, 2020.

ALMEIDA, E. I. B.; RIBEIRO, W. S.; COSTA, L. C.; LUCENA, H. H.; BRBOSA, J. A.. Levantamento de perdas em hortaliças frescas na rede varejista de Areia (PB). Revista Brasileira de Agropecuária Sustentável (RBAS), v.2, n.1, p.53-60, 2012. DOI: https://doi.org/10.21206/rbas.v2i1.58

CHAGAS, T. L. K.; BARBOSA, C. A. C.; SORIANI, R.; SANTOS, E. D.; LEITE, C. A. P.. Conservação de frutos de pimentão em pós-colheita submetidos a duas condições de armazenamento: temperatura ambiente e refrigeração. Revista Terra \& Cultura, v.34, 117-127, 2018.

DAMATTO JÚNIOR, E. R.; GOTO, R.; RODRIGUES, D. S.; VICENTINE, N. M.; CAMPOS, A. J.. Qualidade de pimentões amarelos colhidos em dois estádios de maturação. Revista Cientifica Eletrônica de Agronomia, Garça, v.17, n.1, p.2330, 2010.

FERREIRA, S. M. R.; QUADROS, D. A.; KARKLE, E. N. L.; LIMA, J. J.; TULLIO, L. T.; FREITAS, R. J. S.. Qualidade pós-colheita do tomate de mesa convencional e orgânico. Ciência e Tecnologia Alimentar, Campinas, v.30, n.4, p.858-864, 2010. DOI: http://dx.doi.org/10.1590/S0101-20612010000400004

FREITAS JÚNIOR, F. G. B. F.; SANTOS, M. P.; MOURA, M. S.; DUARTE, L. G.; MACEDO, K. B. C.; SILVA, M. S.; ALMEIDA, E. I. B.; NEVES JUNIOR, A. C. V.; ARAÚJO, J. R. G.; OLIVEIRA, L. B. T.. Uso de embalagem plástica e comestível para conservação de goiaba sob diferentes condições de armazenamento. Revista Ibero-Americana de Ciências Ambientais, v.11, n.4, p.463-473, 2020. DOI: https://doi.org/10.6008/CBPC2179-6858.2020.004.0039

GRIGIO, M. L.; NEVES, L. C.; TOSIN, J. M.; NASCIMENTO, C. R.; CHAGAS, E. A; VIEITES, R. L.. Efeito da modificação atmosférica em goiabas var. Paluma na redução de danos mecânicos em pós colheita. Revista Agro@mbiente, v.5, p.57-65, 2011. DOI: http://dx.doi.org/10.18227/19828470ragro.v5i1.406

GUERRA, A. M. N. M.; FERREIRA, J. B. A.; COSTA, A. C. M.; TAVARES, P. R. F.; MARACAJÁ, P. B.; COELHO, D. C.; ANDRADE, M. E. L.. Perdas pós-colheita em tomate, pimentão e cebola no mercado varejista de Santarém - PA. Agropecuária científica no semiárido, v.10, n.3, p.08-17, 2014. DOI: http://dx.doi.org/10.30969/acsa.v10i3.531
ISO. International Organization for Standardization. 2173: Fruit and vegetable products: Determination of soluble solids, Refractometric method. Geneva: ISO, 2003.

MONTEIRO NETO, J. L. L.; ARAÚJO, W. F.; VILARINHO, L. B. O.; SILVA, E. S.; ARAÚJO, W. B. L.; SAKAZAKI, R. T.. Produção de mudas de pimentão (Capsicum annuum L.) em diferentes ambientes e substratos. Revista Brasileira de Ciências Agrárias, Recife, v.11, n.4, p.289-297, 2016. DOI: http://doi.org/10.5039/agraria.v11i4a5395

MOREIRA, E. G. S.; SANCHES, A. G.; SILVA, M.; COSTA, J.; COSME, S.; CORDEIRO, C. A. M.. Utilização de filme comestível na conservação pós-colheita do pimentão 'Magali'. Scientia Agraria Paranaensis, v.16, n.1, p.120-126, 2017.

OSHIRO, A. M.; DRESCH, D. M.; SCALON, S. P. Q.. Preservação de goiabas 'Pedro Sato' armazenadas sob atmosfera modificada em refrigeração. Revista de Ciências Agrárias, v.35, n.1, p.213-221, 2012.

RIBEIRO, W. S.; ALMEIDA, E. I. B.; COSTA, L. C.; CARNEIRO, G. G.; BARBOSA, J. A.. Perdas pós-colheita de pimentão (Capsicum annuum) no mercado atacadista da EMPASA-CG. Tecnologia e Ciência Agropecuária, João Pessoa, v.5, n.1, p.53-56, 2011.

ROCHA, P. A.. Produção de pimentão sob diferentes estratégias de irrigação com e sem cobertura do solo, no semiárido Baiano. Dissertação (Mestrado em Produção vegetal) - Instituto Federal de Educação, Ciência e Tecnologia Baiano, Guanambi, 2017.

SANCHES, A. G.; SILVA, M. B.; MOREIRA, E. G. S.; CORDEIRO, C. A. M.. Relação entre a embalagem e a temperatura de armazenamento na conservação do pimentão vermelho cv. Rubi. Revista Acta Iguazu, Cascavel, v.4, n.4, p.1-12, 2015.

SILVA, E. O.; PINTO, P. M.; JACOMINO, A. P.; SILVA, L. T.. Processamento Mínimo de Produtos Hortifrutícolas. Fortaleza: Embrapa Agroindústria Tropical, 2011.

SNEATH, P. H.; SOKAL, R. R.. Numerical taxonomy: the principles and practice of numerical classification. San Francisco: W. H. Freeman, 1973.

VESPUCCI, I. L.; SILVA, D. D. A.; MACHADO, V. S.; CAMPOS, A. J.. Conservação de maracujá silvestre sob atmosfera modificada passiva. Revista Eletrônica de Educação da Faculdade Araguaia, v.13, n.3, p.32-43, 2018. DOI: http://dx.doi.org/10.1590/S0103-84782010005000028

VILAS-BOAS, B. M.; SIQUEIRA, H. H.; LEME, S. C.; LIMA, L. C. O.; ALVES, T. C.. Conservação de pimentão verde minimamente processado acondicionado em diferentes embalagens plásticas. Pesquisa Agropecuária Tropical, v.42, n.1, p.34-39, 2012. DOI: https://doi.org/10.1590/S198340632012000100005

A CBPC - Companhia Brasileira de Produção Científica (CNPJ: 11.221.422/0001-03) detém os direitos materiais desta publicação. Os direitos referem-se à publicação do trabalho em qualquer parte do mundo, incluindo os direitos às renovações, expansões e disseminações da contribuição, bem como outros direitos subsidiários. Todos os trabalhos publicados eletronicamente poderão posteriormente ser publicados em coletâneas impressas sob coordenação da Sustenere Publishing da Companhia Brasileira de Produção Científica e seus parceiros autorizados. Os (as) autores (as) preservam os direitos autorais, mas não têm permissão para a publicação da contribuição em outro meio, impresso ou digital, em português ou em tradução. 